\title{
Pulmonary vasculitis associated with cholangiocarcinoma of liver
}

\author{
E.L.C. Ong, S. Evans and S.P. Hanley
}

Department of Chest Diseases, Monsall Hospital, Newton Heath, Manchester M10 8WR, UK.

\begin{abstract}
Summary: A 62 year old woman presented with an acute pulmonary vasculitis which responded to treatment with oral steroids. Investigations over one year revealed a cholangiocarcinoma of the liver. The association of vasculitis with neoplastic diseases remains a diagnostic challenge.
\end{abstract}

\section{Introduction}

Cutaneous and systemic vasculitides are well recognized to occur in association with neoplastic disease such as lymphoproliferative disorders, melanoma and renal cell carcinoma, and may precede their diagnosis by up to 6 years. ${ }^{1-7}$ We report a previously unrecorded association between an acute steroid responsive pulmonary vasculitis and the finding of an hepatic cholangiocarcinoma one year later.

\section{Case report}

A previously fit 62 year old Caucasian dental receptionist presented in June 1987 with a 10 day history of pyrexia, malaise and progressive dyspnoea. She had smoked for a total of 30 pack years, and had a history of allergy to nickel. She had received her first dose of hepatitis B vaccine (Hep-vax, a plasma-derived vaccine) three months previously, and oral ampicillin for 5 days prior to presentation. On examination, she was febrile $\left(39.5^{\circ} \mathrm{C}\right)$, and tachypnoeic. Her pulse was $90 /$ minute, in sinus rhythm, jugular venous pressure was elevated at $3 \mathrm{~cm}$, and blood pressure was 120/70 $\mathrm{mmHg}$. On auscultation a third heart sound was present with a short systolic murmur heard over the whole precordium. There were widespread bilateral inspiratory crackles over both lung fields.

Investigations: haemoglobin $11.2 \mathrm{~g} / \mathrm{dl}$, white cell count $23.0 \times 10^{9} / 1(91 \%$ neutrophils $7 \%$ lymphocytes $1 \%$ monocytes, $1 \%$ eosinophils), plasma viscosity 2.08 cP (normal 1.50-1.72), sodium $129 \mathrm{mmol} / \mathrm{l}$, potassium $3.6 \mathrm{mmol} / 1$, chloride $90 \mathrm{mmol} / \mathrm{l}$, bicarbonate 29 $\mathrm{mmol} / \mathrm{l}$, creatinine $109 \mu \mathrm{mol} / \mathrm{l}$, urea $9.8 \mathrm{mmol} / \mathrm{l}$, albumin 23, total bilirubin $14 \mu \mathrm{mol} / \mathrm{l}$, alkaline phosphatase $293 \mathrm{IU} / 1$ (normal 35-105), aspartate

Correspondence: E.L.C. Ong M.Sc., M.R.C.P., D.T.M.H. Accepted: 29 March 1989 transaminase $137 \mathrm{IU} / 1$ (normal 0-35), alanine transaminase $53 \mathrm{IU} / 1$ (normal 0-35), gammaglutamyltransferase $210 \mathrm{IU} / 1$ (normal 0-30). The arterial blood gas sampling on air showed $\mathrm{pH} 7.42$ (7.36-7.45), $\mathrm{PCO}_{2}$ $35.5 \mathrm{mmHg}(35-45), \mathrm{PO}_{2} 65.8 \mathrm{mmHg}(85-105)$. A chest radiograph (Figure 1) showed marked interstitial shadowing in both lungs. The 12-lead electrocardiograph showed no acute changes. Autoantibody screen was negative. Immunoglobin levels were normal. Hepatitis B core antibody was negative. Paired serology for Mycoplasma pneumoniae, Legionella pneumophila and Chlamydia psittaci was unremarkable.

An initial diagnosis of pulmonary oedema was made but when she did not respond with frusemide, ampicillin and erythromycin were added. After 48 hours she developed a generalized tender maculo-

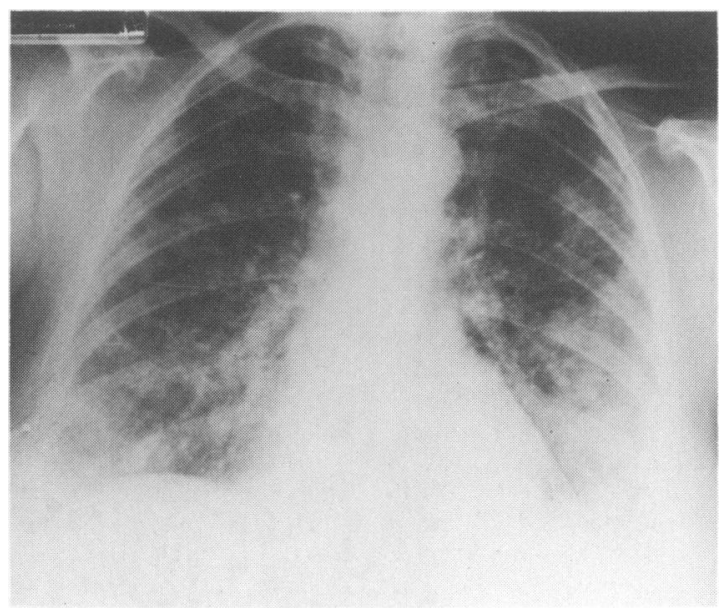

Figure 1 Chest X-ray showing marked interstitial shadowing in both lung fields. 
papular rash, considered to be a drug-induced rash, and became more dyspnoeic. Repeat chest radiographs showed worsening of the interstitial shadowing. Bronchoscopy and transbronchial biopsy was performed. Microscopy and culture of bronchoalveolar lavage fluid, and histology of the lung biopsies were normal. Abdominal ultrasound including the liver was normal. She continued to deteriorate and an open lung biopsy was eventually undertaken, the histology (Figure 2) of which showed a vasculitic picture; subsequent section and review of the transbronchial biopsy revealed similar changes. On starting treatment with prednisolone with an initial dose of $60 \mathrm{mg} /$ day she improved rapidly and was discharged home.
On subsequent review whilst on a maintenance dose of prednisolone reduced to $12.5 \mathrm{mg}$ /day, fluctuating liver function tests were noted with the alkaline phosphatase varying from 88 to $220 \mathrm{IU} / \mathrm{l}$, gamm glutamyl transferase from 130 to $226 \mathrm{IU} / 1$ and alanine transaminase from 8 to $35 \mathrm{IU} / 1$. Repeat blood coun showed a persistent macrocytosis with a normat: vitamin B12 and folate, and unremarkable marrow aspirate. Lung function tests showed a restrictive pattern with progressive improvement but the diffusion never improved to more than $55 \%$ of predicted. Her chest radiograph returned to normate Clinically she maintained her improvement except fof an episode of herpes zoster affecting the right sacral 1 sot

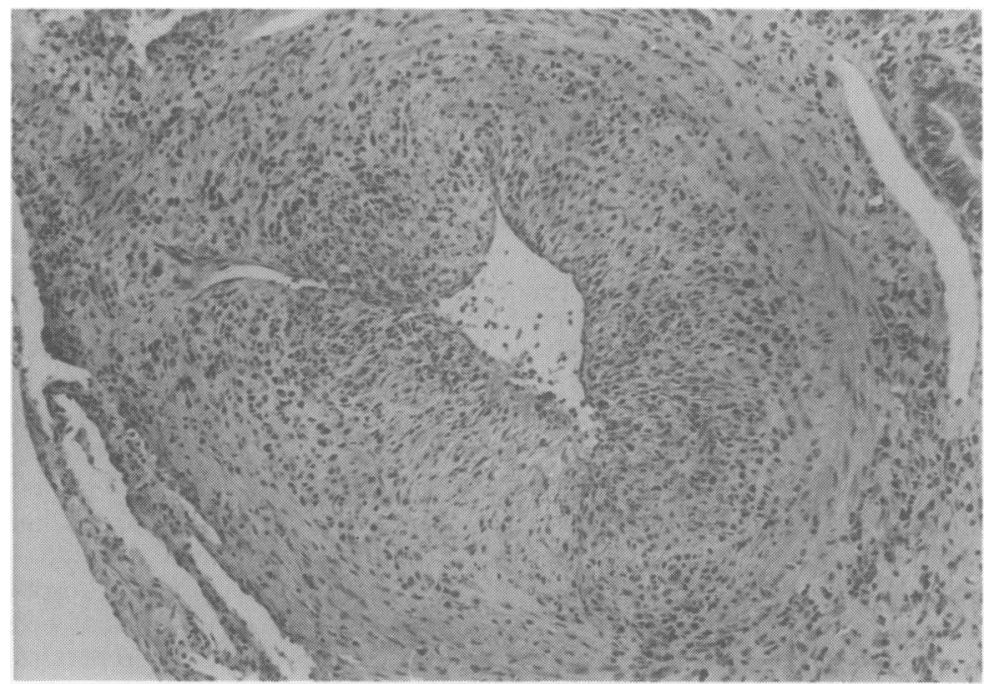

Figure 2 Lung tissue showing vasculitis involving medium sized arteries. These vessels showed marked intimal fibrosis and infiltrate with acute and chronic inflammatory cells. (H \& E x 75)

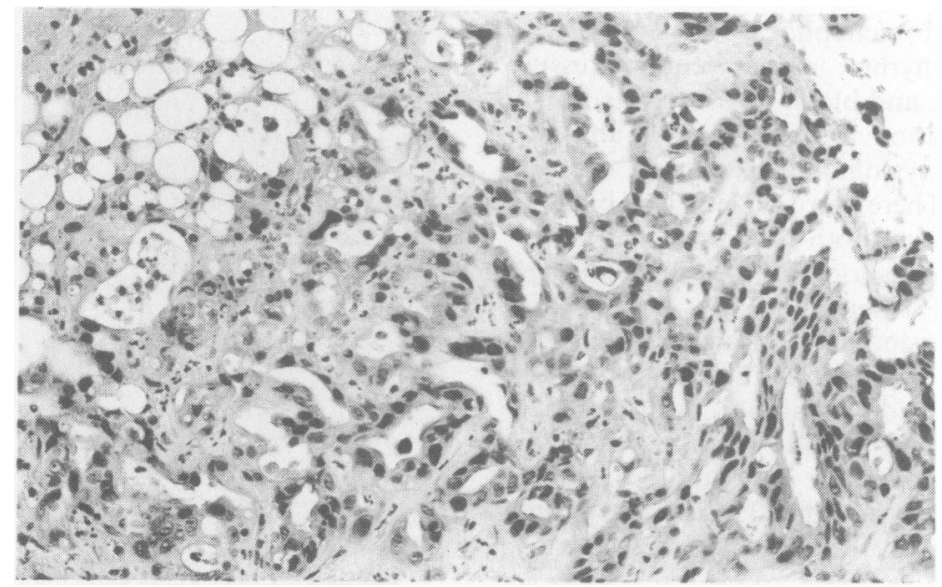

Figure 3 Liver tissue showing cholangiocarcinoma with severe steatosis. (H. \& E. x 45) 
and 2nd dermatomes treated with acyclovir, and an accidental fracture of her left hip. A sustained deterioration in her liver function tests led to a repeat abdominal ultrasound which showed a mass of poor echogenicity measuring $10 \mathrm{~cm}$ in diameter between the left and right lobes of the liver in the region of the gall-bladder suggestive of a neoplasm; this was confirmed by computed-axial tomographic scan. A percutaneous needle biopsy showed cholangiocarcinoma of the liver (Figure 3).

\section{Discussion}

The differential diagnosis of a vasculitis is extensive; neoplastic disorders such as lymphoproliferative and myeloproliferative malignancies are increasingly recognized to be an associated feature. ${ }^{8}$ We are not aware of any previous documented reports of pulmonary vasculitis associated with cholangiocarcinoma of the liver.

\section{References}

1. McCombs, R.P. Systemic "allergic" vasculitis: clinical and pathological relationships. JAMA 1965, 194: 1059-1064.

2. Sams, W.R. Jr, Harville, D.D \& Winkelmann, R.K. Necrotizing vasculitis associated with lethal reticuloendothelial diseases. Br J Dermatol 1968, 80: 555-560.

3. Elkon, K.B., Hughes, G.R.V., Catovsky, D. et al. Hairy cell leukaemia with polyarteritis nodosa. Lancet 1979, ii: 280-282.

4. Copeman, P.W.M. \& Ryan, T.J. The problems of classification of cutaneous angiitis with reference to histopathology and pathogenesis. Br J Dermatol 1970, 82 (suppl 5) : 2-14.

5. Greco, F.A., Kolins, J., Raijoub, R.K. \& Brereton, H.D. Hodgkin's disease and granulomatous angiitis of the central nervous system. Cancer 1976, 38: 2027-2032.
It is interesting to speculate whether the hepatitis B vaccination could have immunologically unmasked the underlying malignancy by manifesting itself as a vasculitis. The vaccine itself is not known to cause vasculitis; however, a possible association between influenza vaccination and small-vessel vasculitis had been previously documented. ${ }^{9}$

Recognition of the association between certain vasculitic syndromes and neoplastic diseases remains a diagnostic challenge, we suggest that such cases be closely monitored and investigated as appropriate if no apparent causes are found in the initial onset of the illness.

\section{Acknowledgements}

We thank Dr P. Haselton, Consultant Histopathologist, Wythenshawe Hospital, Manchester and Dr D. de Kretser, Consultant Pathologist, North Manchester General Hospital for providing and reporting Figures 2 and 3 respectively.

6. Hoag, G.N. Renal cell carcinoma and vasculitis: report of two cases. J Surg Oncol 1987, 35: 35-38.

7. Cupps, T.R. \& Fauci, A.S. Neoplasm and systemic vasculitis: a case report. Arthritis Rheum 1982, 4:00 475-476.

8. Longley, S., Caldwell, J.R. \& Panush, R.S. Paraneoplastic vasculitis: Unique syndrome of cutaneous angiitis and arthritis associated with myeloproliferative disorders. $\mathrm{Am}$ $J$ Med 1986, 80: 1027-1030.

9. Blumberg, S., Bienfang, D.\& Kantrowitz, F.G. A possible association between influenza vaccination and smallvessel vasculitis. Arch Intern Med 1980, 140: 847-848. 